\title{
Effect of MWCNT on Thermal, Mechanical, and Morphological Properties of Polybutylene Terephthalate/Polycarbonate Blends
}

\author{
C. P. Rejisha, S. Soundararajan, N. Sivapatham, and K. Palanivelu \\ Department of Plastics Technology, Central Institute of Plastics Engineering and Technology (CIPET), Chennai, \\ Tamil Nadu 600 032, India \\ Correspondence should be addressed to S. Soundararajan; bssrajan@yahoo.co.in
}

Received 15 January 2014; Revised 23 March 2014; Accepted 23 March 2014; Published 24 April 2014

Academic Editor: Cornelia Vasile

Copyright (C) 2014 C. P. Rejisha et al. This is an open access article distributed under the Creative Commons Attribution License, which permits unrestricted use, distribution, and reproduction in any medium, provided the original work is properly cited.

\begin{abstract}
This paper evaluated the effect of multiwall carbon nanotube (MWCNT) on the properties of PBT/PC blends. The nanocomposites were obtained by melt blending MWCNT in the weight percentages $0.15,0.3$, and $0.45 \mathrm{wt} \%$ with PBT/PC blends in a high performance corotating twin screw extruder. Samples were characterized by tensile testing, dynamic mechanical analysis, thermal analysis, scanning electron microscopy, and X-ray diffraction. Concentrations of PBT and PC are optimized as $80: 20$ based on mechanical properties. A small amount of MWCNT shows better increase in the thermal and mechanical properties of the blends of PBT/PC nanocomposite when compared to nanoclays or inorganic fillers. The ultimate tensile strength of the nanocomposites increased from $54 \mathrm{MPa}$ to $85 \mathrm{MPa}$ with addition of MWCNT up to $0.3 \%$ and then decreased.The tensile modulus values were increased to about $60 \%$ and the flexural modulus was more than about $80 \%$. The impact strength was also improved with $20 \%$ PC to about $60 \%$ and with $0.15 \%$ MWCNT to about $50 \%$. The HDT also improved from $127^{\circ} \mathrm{C}$ to $205^{\circ} \mathrm{C}$. It can be seen from XRD result that the crystallinity of $\mathrm{PBT}$ is less affected by incorporating MWCNT. The crystallizing temperature was increased and the MWCNT may act as a strong nucleating agent.
\end{abstract}

\section{Introduction}

Polyesters like PBT and PET are semicrystalline and possess high stiffness, hardness, dimensional stability, good bearing strength, good electrical properties, excellent flow characteristics, and good resistance to chemicals but have low impact strength. PC has excellent impact strength.

Polymer blends are developed in an effort to meet cost/performance required in many engineering applications. In these blends, it is important to establish some level of interfacial adhesion between the components in order to achieve the necessary toughness. The required bonding is achieved in some commercial blends, for example, polybutylene terephthalate/polyethylene terephthalate (PBT/PET), polybutylene terephthalate/polycarbonate $(\mathrm{PBT} / \mathrm{PC})$, as a result of the partial miscibility between the blend components [1-5]. PCPBT is useful for car bumpers, front ends by Bayer (trade name: Macro Blend). DSM also recently announced PCPET blends. The PBT/PC finds use in many engineering applications like automotive body panels, in outdoor power, or recreational equipment, appliance housings, telecommunication, and so forth. The PC will improve the impact strength and elongation of PBT since PBT like PET has lower impact strength [6-8]. The various blends of PBT and the properties improvement are also given in [8].

The properties of the high polymer blends can be further improved by compounding with glass fibre or carbon fibre. The recently found carbon nanotube (single-/mutliwall) has the potential to further improve the properties due to their high strength $(\sim 130 \mathrm{GPa})$ and has high aspect ratio (length: few micrometres; diameter: $1 \mathrm{~nm}$ ) [9-12]. The positive effect of nanotubes to polymer properties can be derived directly not only from the MWCNT properties and their volume fraction but also from their influence on morphology, crystallinity [13], and glass transition temperature [14-16]. Though it imparts good properties, it is very difficult to achieve these fundamental properties in experimental composites due to the need to disperse the individual nanotubes into the matrix and to ensure sufficient interfacial stress transfer between nanotubes and matrix [17]. The main issue 
in the production of carbon nanotube reinforced polymers is to avoid the agglomeration of nanotubes in the polymer matrix [18].

Recent studies on MWCNT with ethylene vinyl acetate (EVA) show improved flame retardancy and thermal properties [19]. Studies on glass fibers-carbon nanotube epoxy composites have been reported [20]. Novel approach for the conductive nanocompounds by using polypyrrole MWCNT also has been published in the literature [21]. Applications of MWCNT composites in aviation industry with various characteristics of CNT and MWCNT are given in this reference [22]. Comparison and analysis of physical properties of carbon nanomaterial doped polymer composites were also reported [23]. Highly electrical conducting PS/MWCNT nanocomposites properties by in situ polymerization were reported [24]. Studies on PC/ABS blends with MWCNT were recently reported [25].

The MWCNT in blends may be useful as an ultraviolet (UV) stabilizer in the outdoor applications like automotive applications with higher mechanical and thermal properties, though the electrical insulation may be little lower. In the present paper, $\mathrm{PBT}$ is melt-blended with $\mathrm{PC}$ in three different formulations $(10,20$, and $30 \mathrm{wt} \%)$. In $80 \%: 20 \%$ ratio PBT and PC, the MWCNTs were melt-dispersed. The influence of MWCNT on the mechanical and thermal properties of the blend was evaluated.

\section{Experimental}

2.1. Materials. PBT (Crastin, CNC010), melting temperature $225^{\circ} \mathrm{C}$, was purchased from DuPont (Chennai, India) and PC (CORNING), melting temperature $220^{\circ} \mathrm{C}$, was procured from Sigma Aldrich (Chennai, India). The multiwall nanotube was supplied by Sun Nanotech Co. Ltd., China.

2.2. Twin Screw Compounding. Melt processing is carried out in Berstorff high performance corotating twin screw extruder (L/D ratio $-30: 1$, capacity $5-30 \mathrm{Kg} / \mathrm{hr}$ ). In the first stage, PBT/PC blends containing different volume percentages $(90: 10,80: 20$, and $70: 30 \%)$ were prepared at a temperature range of $180-250^{\circ} \mathrm{C}$ with a screw speed of $110 \mathrm{rpm}$. In the second stage, the nanocomposite was prepared by compounding different concentrations of MWCNT $(0.15,0.3$, and $0.45 \%)$ with the optimized composition of PBT/PC $(80: 20 \%)$ blend. PBT and PC were dried at $100^{\circ} \mathrm{C}$ for $8 \mathrm{hrs}$ in an aircirculated oven before compounding. Finally, these blended materials were molded at an injection molding machine as per American Society for Testing and Materials (ASTM) standard.

2.3. Testing of PBT/PC Blends and Their MWCNT Composites. Tensile properties were investigated using Universal testing machine (Shimadzu Autograph, model: AG $50 \mathrm{KN}$, Japan) according to ASTM D 638 with a cross-head speed of $50 \mathrm{~mm} /$ minute. The impact strength test is carried out according to ASTM D 256. The test is carried out using an Izod Impact tester (atsfaar, Italy). The specimens have dimensions $63.5 \times 12.7 \times 3 \mathrm{~mm}$, with "V" notch depth of
$2.54 \mathrm{~mm}$ and notch angle $45^{\circ}$. The flexural strength and modulus were done as per ASTM D 790 using the same universal testing machine.

Nonisothermal crystallization analysis was performed by means of a differential scanning calorimeter (PerkinElmer, Pyris Diamond DSC). The standard procedure performed was as follows: samples of about 5-10 $\mathrm{mg}$ were heated from $5^{\circ} \mathrm{C}$ to $250^{\circ} \mathrm{C}$ at a scan rate of $10^{\circ} \mathrm{C} / \mathrm{min}$ and held for $2 \mathrm{~min}$ in order to eliminate any thermal history of the material. Subsequently, the samples were cooled to $50^{\circ} \mathrm{C}$ using scan rate of $10^{\circ} \mathrm{C} / \mathrm{min}$. The heat distortion temperature (HDT) (atsfaar, Italy) of the nanocomposites was measured under load (1.8 MPa) according to ASTM D 648.

Dynamic mechanical analysis measurement was carried out on a thermal analyser (TA Instrument). The materials were cut into strips with length of $60 \mathrm{~mm}$ and thickness of $3 \mathrm{~mm}$. Tests were performed at a frequency of $10 \mathrm{~Hz}$ between $30^{\circ} \mathrm{C}$ and $220^{\circ} \mathrm{C}$ with a ramp of $3^{\circ} \mathrm{C} / \mathrm{min}$. The characteristics of the fracture surface of the samples were investigated after slight gold sputtering, using a field emission scanning electron microscope (SEM-FEG). The wide angle X-ray diffraction (WAXD) analysis was performed with a BRUKER D8 ADVANCE X-ray diffractometer using Ni-filtered $\mathrm{Cu} \mathrm{K \alpha}$ $\mathrm{X}$-ray, and the diffracting intensities were recorded at a step of every $2 \theta$ over the range of $10-40 \theta$. The microstructure of the nanocomposite and the CNT distribution in the polymer blend were observed.

\section{Result and Discussion}

3.1. Dispersion of MWCNTs. Dispersion of MWCNTs is critical in order to improve the mechanical properties. Poor dispersion of MWCNT leads to localized micron-sized agglomerates which can negatively influence the strengthening mechanism of MWCNTs such as crack deflection or crack bridging. If the MWCNTs are well dispersed, they form a three-dimensional physical network thereby effectively enhancing the overall performance of the material.

\subsection{Mechanical Properties}

3.2.1. Effect of Incorporation of PC on the Mechanical Properties of PBT. Mechanical properties of virgin PBT and PBT/PC at different concentrations $(90: 10,80: 20$, and $70: 30 \%)$ are summarized in Table 1. It is observed that on increasing the PC concentration in the blend up to $20 \%$, the mechanical properties increase. This is due to the toughening effect of PC. Above $20 \%$ of PC, the blend shows a decrease in tensile strength and flexural strength. This is due to the higher polarity of PC and semicompatibility with PBT. But, in the case of impact strength, as the concentration of PC increases, the impact strength also increases because the PC has an excellent impact strength compared to that of PBT.

3.2.2. Effect of Loading MWNT on the Mechanical Properties of $P B T / P C$ Blend. Table 2 shows mechanical properties of various MWCNT reinforced composites. It shows that the tensile and flexural strength and modulus (Figure 1) increase on the 


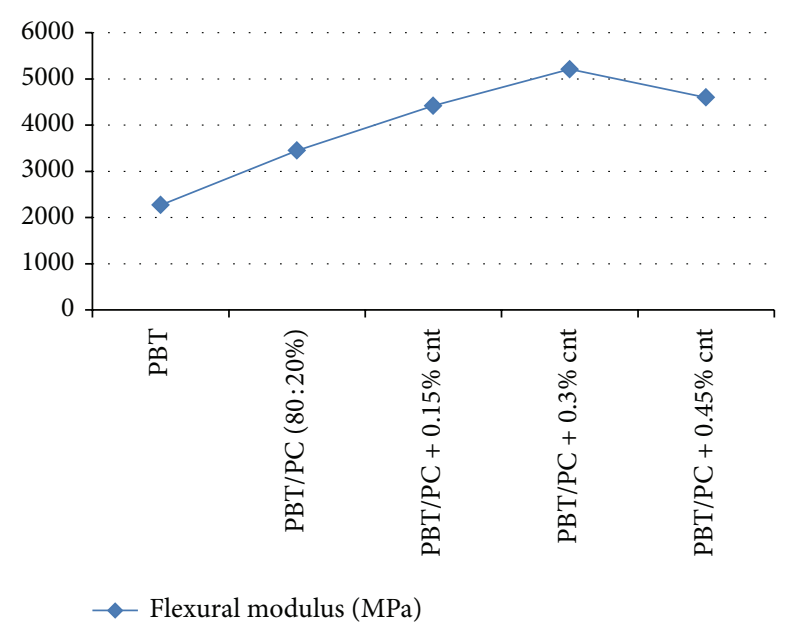

FIgURE 1: Flexural modulus of PBT/PC with MWCNT.

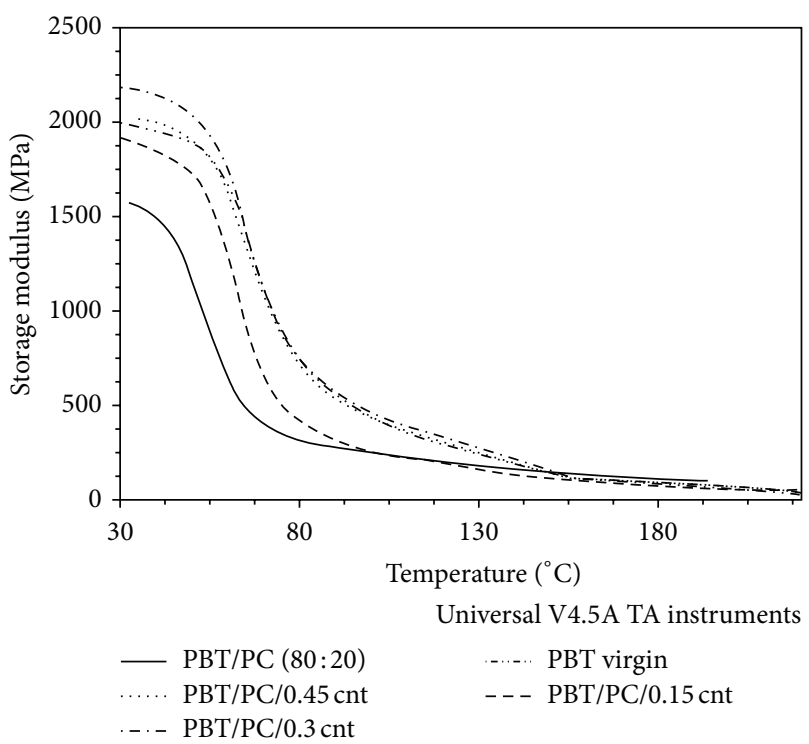

FIGURE 2: Storage modulus of PBT, PBT/PC blends and MWCNT composites.

addition of MWCNT. It can be observed that with an increase from $0.15 \mathrm{wt} \%$ to $0.3 \mathrm{wt} \%$ of MWCNT concentration, the Young's modulus and tensile strength increase enormously. This may be attributed to the better reinforcement of the MWCNT when incorporated in the PBT/PC matrix and hence better performance was observed. On the other hand, the tensile strength reduces by incorporation of $0.45 \mathrm{wt} \%$ of MWCNT. Similar trend was observed with flexural strength and modulus. It may be caused by the disturbance of the PBT crystallization and saturation in this sample. The incorporation of MWCNT on the matrix first increases for $0.15 \%$ and then reduces the impact strength value. This is due to the reinforcing effect of MWCNT on the matrix. The PBT/PC MWCNT composites show higher impact strength values than those of virgin $\mathrm{PBT}$.
TABLE 1: Mechanical properties of PBT and PBT/PC blend at various concentrations.

\begin{tabular}{lccccc}
\hline $\begin{array}{l}\text { Sample } \\
\text { ID }\end{array}$ & $\begin{array}{c}\text { Tensile } \\
\text { strength } \\
(\mathrm{MPa})\end{array}$ & $\begin{array}{c}\text { Tensile } \\
\text { modulus } \\
(\mathrm{GPa})\end{array}$ & $\begin{array}{c}\text { Flexural } \\
\text { strength } \\
(\mathrm{MPa})\end{array}$ & $\begin{array}{c}\text { Flexural } \\
\text { modulus } \\
(\mathrm{GPa})\end{array}$ & $\begin{array}{c}\text { Impact } \\
\text { strength } \\
(\mathrm{J} / \mathrm{m})\end{array}$ \\
\hline $\begin{array}{l}\text { PBT } \\
(100 \%)\end{array}$ & 54 & 2.21 & 72 & 2.27 & 53 \\
$\begin{array}{l}\text { PBT/PC } \\
(90: 10)\end{array}$ & 61 & 2.39 & 79 & 2.91 & 72 \\
$\begin{array}{l}\text { PBT/PC } \\
(80: 20)\end{array}$ & 65 & 2.51 & 87 & 3.45 & 85 \\
$\begin{array}{l}\text { PBT/PC } \\
(70: 30)\end{array}$ & 63 & 2.44 & 83 & 3.02 & 91 \\
\hline
\end{tabular}

\subsection{Thermal Properties}

3.3.1. Heat Distortion Temperature (HDT). The HDT plays an important role in determining the performance of engineering plastics at the elevated temperature. The HDT can be influenced by various factors such as the polymer melt, mold temperature, the nucleating agent, and various processing conditions, which is often related to the mechanical and thermal behavior of the polymer composite. The variations in the HDT values for the PBT, PBT/PC blend, and the nanocomposites are shown in Table 3. The HDT values of the nanocomposites increased enormously with the MWCNT content which is due to the enormous increase in the flexural modulus of the nanocomposites. In the HDT measurement, the ability of the polymeric material to retain stiffness with the increasing temperature is important for a high HDT value. The nanocomposites containing $0.3 \%$ MWCNT show the highest HDT value.

3.3.2. Differential Scanning Calorimetry (DSC). The thermal parameters, melting temperature $\left(T_{m}\right)$, crystallization temperature $\left(T_{c}\right)$, and melting enthalpy $\left(H_{m}\right)$ were obtained from the DSC thermogram. Table 4 shows the DSC thermogram readings.

The melting temperature of PBT is lower in the blends (PBT/PC, 80:20) compared to the virgin PBT. The lowering of this temperature for $\mathrm{PBT} / \mathrm{PC}$ is due to the decreasing concentration of PBT. Incorporation of MWNT causes an increase in delta $H_{m}$ value. The increase is up to $0.3 \%$ of MWCNT. This may be due to the stiffening effect of MWCNT on the matrix. Above $0.3 \%$, the crystallinity of PBT may be affected and hence the reduced $H_{m}$ value.

The heat of fusion values shows very interesting behavior. The $\Delta H_{m}$ value for the PBT/PC blend is lower than the value expected. But this value is less than that of virgin PBT. The PBT/PC blend does not show much variation in $T_{m}$ compared to virgin PBT. This may be due to less disturbance of the crystallinity of PBT in the blend. The nanocomposite shows a higher value than the blend. The crystallization temperature for all nanocomposites is little higher than that of the virgin PBT. Faster cooling can be achieved. The crystallite or spherulites sizes may be reduced and transparency may be improved. 
TABLE 2: Mechanical properties of PBT, PBT/PC blend, and MWCNT composites.

\begin{tabular}{|c|c|c|c|c|c|}
\hline Sample ID & $\begin{array}{c}\text { Tensile strength } \\
(\mathrm{MPa})\end{array}$ & $\begin{array}{c}\text { Tensile modulus } \\
(\mathrm{GPa})\end{array}$ & $\begin{array}{c}\text { Flexural strength } \\
(\mathrm{MPa})\end{array}$ & $\begin{array}{l}\text { Flexural modulus } \\
(\mathrm{GPa})\end{array}$ & $\begin{array}{l}\text { Impact strength, } \\
\text { Izod }(\mathrm{J} / \mathrm{m})\end{array}$ \\
\hline PBT (100\%) & 54 & 2.21 & 72 & 2.27 & 53 \\
\hline $\mathrm{PBT} / \mathrm{PC}(80 \% / 20 \%)$ & 65 & 2.51 & 87 & 3.45 & 85 \\
\hline $\mathrm{PBT} / \mathrm{PC}+0.15 \% \mathrm{MWCNT}$ & 74 & 3.2 & 112 & 4.42 & 79 \\
\hline $\mathrm{PBT} / \mathrm{PC}+0.3 \% \mathrm{MWCNT}$ & 85 & 4.0 & 137 & 5.21 & 72 \\
\hline $\mathrm{PBT} / \mathrm{PC}+0.45 \% \mathrm{MWCNT}$ & 79 & 3.5 & 129 & 4.60 & 64 \\
\hline
\end{tabular}

TABLE 3: HDT values of PBT, PBT/PC blend, and MWCNT composites.

\begin{tabular}{lcc}
\hline $\begin{array}{l}\text { Concentration of } \\
\text { MWCNT }(\%)\end{array}$ & $\begin{array}{c}\text { Concentration of PBT } \\
(\%)\end{array}$ & $\begin{array}{c}\text { H DT [at 0.46 MPa } \\
\text { stress] }\left({ }^{\circ} \mathrm{C}\right)\end{array}$ \\
\hline $0 \%$ & 100 & 127 \\
$0 \%$ & $80: 20$ & 130 \\
$0.15 \%$ & $80: 20$ & 187 \\
$0.3 \%$ & $80: 20$ & 205 \\
$0.45 \%$ & $80: 20$ & 196 \\
\hline
\end{tabular}

3.4. Dynamic Mechanical Analysis (DMA). The viscoelastic nature of the various nanocomposites was characterized by dynamic mechanical analysis. Glass transition temperature $\left(T_{g}\right)$, storage modulus $\left(E^{\mathrm{I}}\right)$, loss modulus $\left(E^{\mathrm{II}}\right)$, and $\tan \delta$ were obtained from DMA. Figure 2 shows the temperature verses storage modulus $E^{\mathrm{I}}$ of $\mathrm{PBT}$, $\mathrm{PBT} / \mathrm{PC}$ blend, and various nanocomposites. It can be observed that the storage modulus of the nanocomposites is higher than that of the PBT/PC blend. In all nanocomposites, the incorporation of MWCNT causes a measurable increase in stiffness. The storage modulus of PBT/PC is increased by the stiffening effect of the nanotubes. This effect is significant at temperature below $T_{g}$ of PBT. This shows that the reinforcing effect of MWCNT is mainly active in the amorphous phase.

The $\tan \delta$ curves of the various blends and MW nanocomposites are shown in Figure 3. It can be seen that $\tan \delta$ peak of the nanocomposites shifted to slightly higher temperature compared to that of pure PBT and becomes broader. This can be explained by the strong interaction between the MWCNT and the matrix. This increase in property diminishes due to the increasing concentration of MWCNT which causes agglomeration in the matrix. The maximum of $\tan \delta$ is taken as the glass transition temperature $\left(T_{g}\right)$ and is almost the same for all the material.

3.5. Scanning Electron Microscopy. Morphology is a major factor in determining the mechanical properties of the polymer blends and multiwall carbon nanocomposites.

Figures 4(a), 4(b), and 4(c) show the microscopic graphs of the fracture morphologies of $\mathrm{PBT} / \mathrm{PC}$ at different concentrations of MWCNTs. In MWCNT, filled PBT/PC nanocomposites show a uniformed dispersion PC in PBT matrix in presence of MWCNT in the polymer matrix at lower concentration.

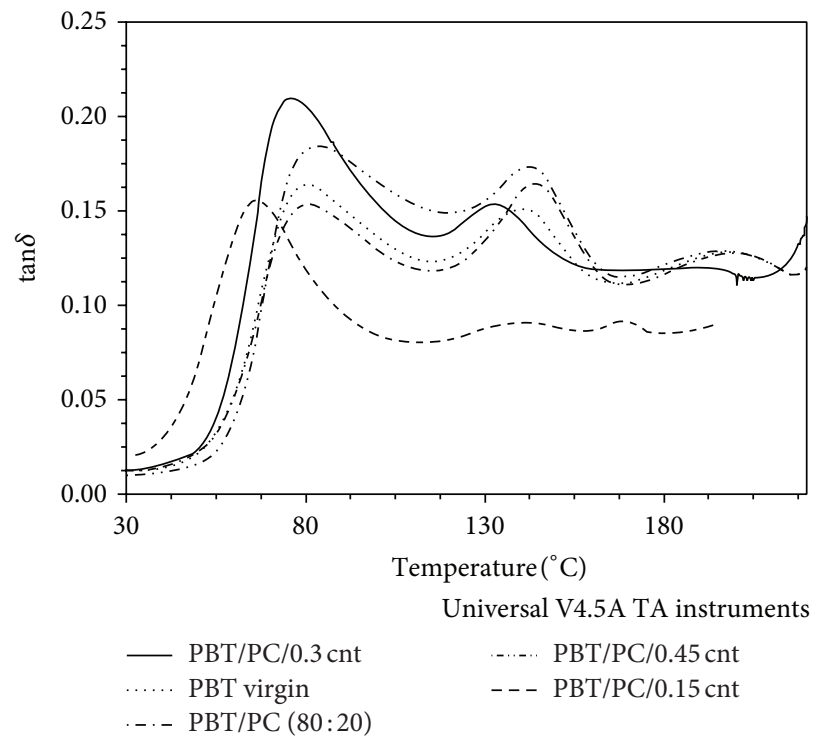

Figure 3: Tan delta of virgin PBT, PBT/PC blends, and MWCNT composites.

3.6. X-Ray Diffraction. Wide angle X-ray analysis was conducted on the PBT, PBT/PC nanocomposites to investigate the effect on the structure of the nanocomposites; WAXD patterns of the nanocomposites are shown in Figure 5. The characterization peaks of pure PBT were also observed for the nanocomposites and the position of the peaks remained almost unchanged with the introduction of MWCNT, despite some change in the peak intensity. The intensity of the peak is less in $\mathrm{PBT} / \mathrm{PC}$ when compared to the nanocomposite due to the semicrystalline nature of PC which reduces the intensity of the peak. This result shows that the incorporation of MWCNT into the PBT and PBT/PC matrix does not change the crystal structure of the nanocomposites. The crystallinity of the nanocomposites was slightly increased with the introduction of MWCNT, which may be explained by the super cooling temperature.

In the nanocomposite, MWCNTs act as a strong nucleating agent in the PBT matrix, and the crystalline temperature shifts to higher temperature, implying that the super cooling of the nanocomposite was increased with the introduction of MWCNT. When the polymer crystallized with more super cooling, it crystallized more perfectly than the less super cooling, and thus the crystallinity of nanocomposite may 
TABLE 4: DSC data of the virgin PBT, PBT/PC blend, and MWCNT.

\begin{tabular}{lccc}
\hline Sample ID & $\begin{array}{c}\text { Melting temperature } \\
T_{m}\left({ }^{\circ} \mathrm{C}\right)\end{array}$ & $\begin{array}{c}\text { Crystallization temperature } \\
T_{c}\left({ }^{\circ} \mathrm{C}\right)\end{array}$ & 187.00 \\
\hline PBT $(100 \%)$ & 225.00 & 185.36 & 26 \\
PBT/PC $(80 / 20)$ & 220.38 & 197.22 & 15 \\
PBT/PC $(80 / 20)+0.15 \%$ MWCNT & 222.71 & 202.29 & 20 \\
PBT/PC $(80 / 20)+0.3 \%$ MWCNT & 225.97 & 199.94 & 24 \\
PBT/PC $(80 / 20)+0.45 \%$ MWCNT & 223.64 & & 21 \\
\hline
\end{tabular}

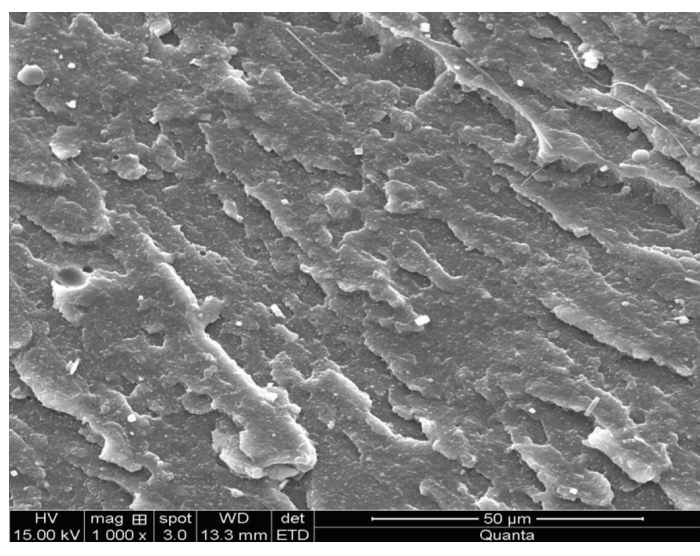

(a)

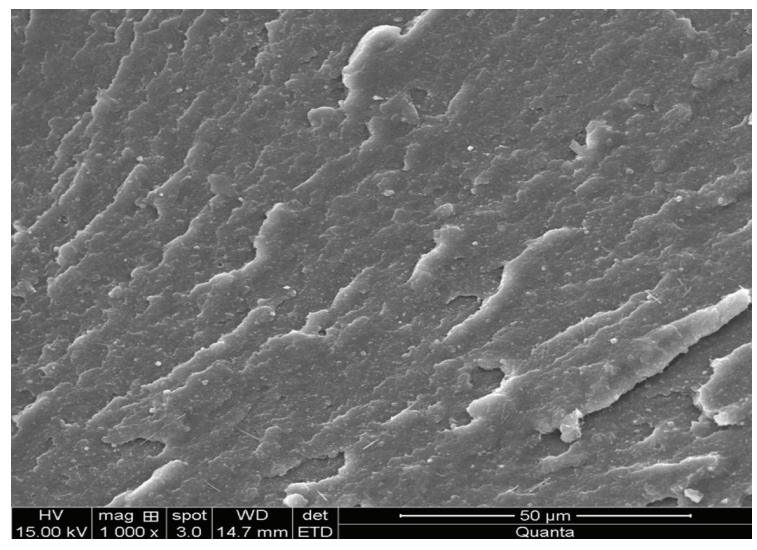

(b)

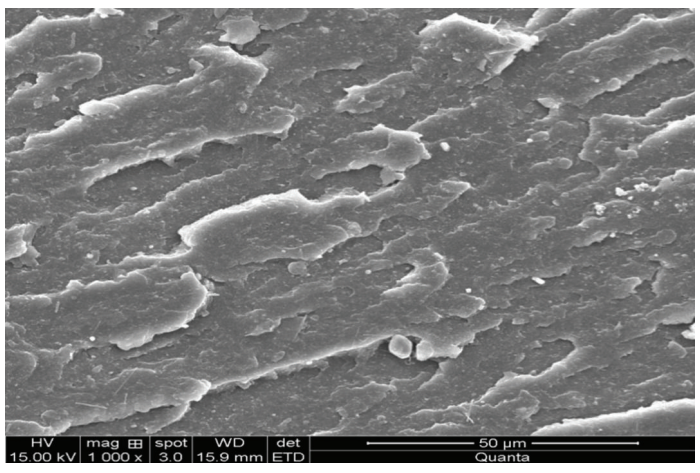

(c)

Figure 4: (a) SEM images of PBT/PC/0.15\% MWCNT, (b) SEM images of PBT/PC/0.3\% MWCNT, (c) and SEM images of PBT/PC/0.45\% MWCNT.

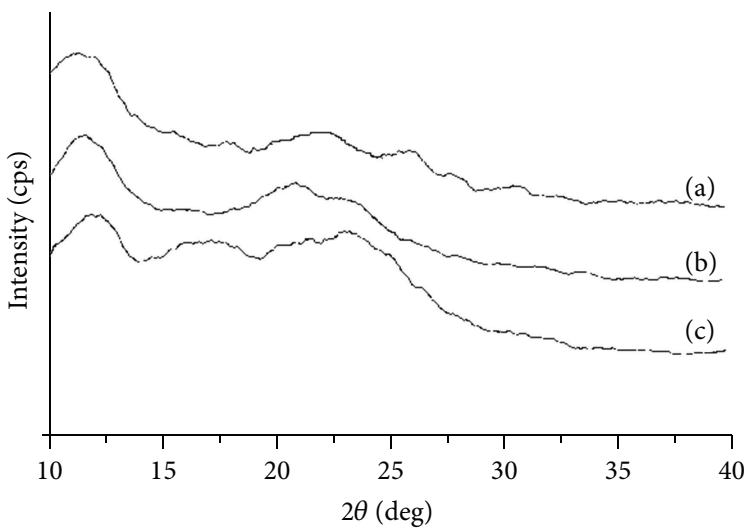

Figure 5: XRD graph of (a) PBT/PC/0.3\% MWCNT, (b) virgin PBT, and (c) PBT/PC blend. 
be slightly increased with the introduction of MWCNT. Hence, the mechanical properties like tensile strength, flexural strength, and modulus increased and the impact strength was decreased.

In the nanocomposite, MWCNTs act as a strong nucleating agent in the PBT matrix, and the crystalline temperature shifts to higher temperature, implying that the super cooling of the nano composite was increased with the introduction of MWCNT. When the polymer crystallized with more super cooling, it crystallized more perfectly than the less super cooling, and thus the crystallinity of nanocomposite slightly increased with the introduction of MWCNT. Hence, the mechanical properties like tensile strength, flexural strength, and modulus were increased up to $0.30 \%$. The impact strength was increased first and then decreased but was higher than that of $\mathrm{PB}$.

\section{Conclusion}

The ultimate tensile strength of the nanocomposites increased from $54 \mathrm{MPa}$ to $85 \mathrm{MPa}$ with addition of MWCNT up to $0.3 \%$ and then decreased. The tensile modulus values were increased to about $60 \%$ and the flexural modulus was more than about $80 \%$. The impact strength was also $60 \%$ improved with $20 \%$ PC and 50\% improved with $0.15 \%$ MWCNT. The HDT also improved from $127^{\circ} \mathrm{C}$ to $205^{\circ} \mathrm{C}$. It can be seen from XRD result that the crystallinity of PBT is less affected by incorporating MWCNT. The crystallization temperature for all nanocomposites is little higher than that of the virgin PBT. Faster cooling can be achieved. Hence, the mechanical properties like tensile strength, flexural strength, and modulus were increased up to $0.30 \%$. The impact strength was also improved with $20 \%$ PC to about $60 \%$ and with $0.15 \%$ MWCNT to about $50 \%$ and then decreased but was higher than that of PBT. The results suggest that the MWCNts act as strong reinforcement in PBT/PC blends. The crystallizing temperature was increased and the MWCNT may act as strong nucleating agent. The nanotubes are well dispersed in the polymer matrix (up to $0.3 \%$ of MWCNT).

The result shows that a small amount of MWCNT is enough to improve the mechanical properties of the PBT/PC matrix. In the present work, it has been shown that PBT/PC/MWCNT thermoplastic nanocomposites can be produced with tensile strength, tensile modulus, flexural strength, and flexural modulus considerably higher than those of PBT or PBT/PC blend. In conclusion, the addition of MWCNT offers a simple and effective means to produce nanocomposites. The MWCNT in PBT/PC blends may be useful as an ultraviolet (UV) stabilizer in the outdoor applications like automotive applications with higher mechanical and thermal properties though the electrical insulation may be little lower.

\section{Conflict of Interests}

The authors declare that there is no conflict of interests regarding the publication of this paper.

\section{References}

[1] S. Y. Hobbs, V. L. Groshans, M. E. J. Dekkers, and A. R. Shultz, "Erratum," Polymer Bulletin, vol. 17, no. 5, p. 496, 1987.

[2] S. Y. Hobs, M. E. J. Dekkers, and V. H. Watkins, "Toughened blends of poly(butylene terephthalate) and BPA polycarbonate," Journal of Materials Science, vol. 23, no. 4, pp. 1219-1224, 1988.

[3] M. E. J. Dekkers, S. Y. Hobbs, and V. H. Watkins, “Toughened blends of poly(butylene terephthalate) and BPA polycarbonate - part 2 Toughening mechanisms," Journal of Materials Science, vol. 23, no. 4, pp. 1225-1230, 1988.

[4] J. D. Keitz, J. W. Barlow, and D. R. Paul, "Polycarbonate blends with stryene/acrylonitrile copolymers," Journal of Applied Polymer Science, vol. 29, no. 10, pp. 3131-3145, 1984.

[5] R. A. Mendelson, "Miscibility and deformation behavior in some thermoplastic polymer blends containing poly(styreneco-acrylonitrile)," Journal of Polymer Science A, Polymer Physics, vol. 23, no. 10, pp. 1975-1995, 1985.

[6] J. A. Brydson, Plastics Materials, Butterworth Heinemann, Oxford, UK, 7th edition, 2011.

[7] L. A. Utarcki, Commerciasl Polymer Blends, Chapman \& Hall, London, UK, 1998.

[8] L. A. Utarcki, Polymer Blends Handbook, vol. 1, Kluwer Academic, London, UK, 2002.

[9] O. Lourie and H. D. Wagner, "Transmission electron microscopy observations of fracture of single-wall Carbon nanotubes under axial tension," Applied Physics Letters, vol. 73, no. 24, pp. 3527-3529, 1998.

[10] O. Lourie and H. D. Wagner, "Evaluation of Young's modulus of Carbon nanotubes by micro-Raman spectroscopy," Journal of Materials Research, vol. 13, no. 9, pp. 2418-2422, 1998.

[11] J. Sandler, M. S. P. Shaffer, T. Prasse, W. Bauhofer, K. Schulte, and A. H. Windle, "Development of a dispersion process for Carbon nanotubes in an epoxy matrix and the resulting electrical properties," Polymer, vol. 40, no. 21, pp. 5967-5971, 1999.

[12] O. Lourie, D. M. Cox, and H. D. Wagner, "Buckling and collapse of embedded Carbon nanotubes," Physical Review Letters, vol. 81, no. 8, pp. 1638-1641, 1998.

[13] J. Sandler, G. Broza, M. Nolte, K. Schulte, Y.-M. Lam, and M. S. P. Shaffer, "Crystallization of Carbon nanotube and nanofiber polypropylene composites," Journal of Macromolecular Science-Physics, vol. 42, no. 3-4, pp. 479-488, 2003.

[14] F. H. Gojny and K. Schulte, "Functionalisation effect on the thermo-mechanical behaviour of multi-wall Carbon nanotube/epoxy-composites," Composites Science and Technology, vol. 64, no. 15, pp. 2303-2308, 2004.

[15] C. Zhao, L. Ji, H. Liu et al., "Functionalized Carbon nanotubes containing isocyanate groups," Journal of Solid State Chemistry, vol. 177, no. 12, pp. 4394-4398, 2004.

[16] H. Kong, C. Gao, and D. Yan, "Functionalization of multiwalled Carbon nanotubes by atom transfer radical polymerization and defunctionalization of the products," Macromolecules, vol. 37, no. 11, pp. 4022-4030, 2004.

[17] S. Barrau, P. Demont, A. Peigney, C. Laurent, and C. Lacabanne, "Dc and ac conductivity of Carbon nanotubes-polyepoxy composites," Macromolecules, vol. 36, no. 14, pp. 5187-5194, 2003.

[18] M. Lamy de la Chapelle, C. Stéphan, T. P. Nguyen et al., "Raman characterization of singlewalled Carbon nanotubes and PMMA-nanotubes composites," Synthetic Metals, vol. 103, no. 1-3, pp. 2510-2512, 1999. 
[19] A. K. Ghosh, "Reduced graphene oxide/ethylene vinyl acetate co-polymer composite with improved thermal stability and flame retardancy," Journal of Polymer Materials, vol. 29, pp. 411421, 2012.

[20] R. Ramlee, M. Mariatti, Z. K. Mohd Ishak, and A. R. Mohamed, "Properties of glass Fiber-Carbon nanotube (CNT)/Epoxy composites," Journal of Polymer Materials, vol. 30, no. 1, pp. 103116, 2013.

[21] K. V. Yeole and S. T. Mhaske, "Novel approach for the preparation of conductive nano composites by using Poly Pyrolle MWCNT," Journal of Polymer Materials, vol. 29, pp. 145-151, 2012.

[22] M. Verma, "Applications of nano technology in aviation industry," in Proceedings of the International Symposium on Macroand Supramolecular Architectures and Materials (MAM '12), V. Rajaendran, P. Paramasivam, and K. E. Geckler, Eds., pp. 253260, Blooms Bury, New Delhi, India, 2012.

[23] S. Bal and S. Bhattacharjee, "Comparison and analysis of physical properties of Carbon nano material doped polymer composites," in Proceedings of the International Symposium on Macro- and Supramolecular Architectures and Materials (MAM '12), V. Rajaendran, P. Paramasivam, and K. E. Geckler, Eds., pp. 69-74, Blooms Bury, New Delhi, India, 2012.

[24] N. Kumar, S. Vastava, and B. B. Khatua, "Highly electrical conducting polystyrene/MWCNT nanocomposites prepared by insitu polymerization," in Advancements in Polymeric Materials, CIPET, Chennai, India, 2011.

[25] Z.-Y. Xiong, L. Wang, Y. Sun, Z.-X. Guo, and J. Yu, "Migration of MWCNTs during melt preparation of ABS/PC/MWCNT conductive composites via PC/MWCNT masterbatch approach," Journal of Polymer, vol. 54, no. 1, pp. 447-455, 2013. 

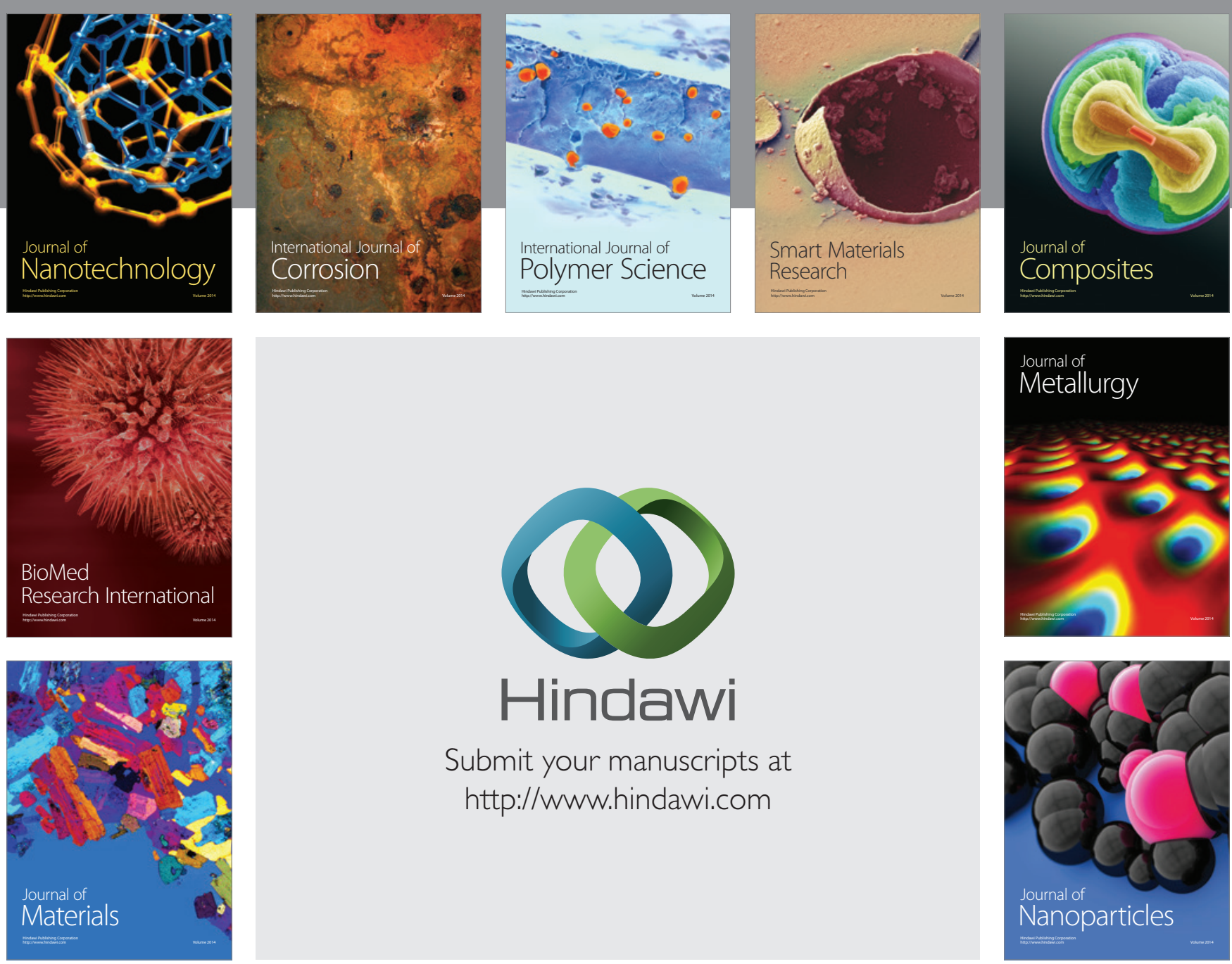

Submit your manuscripts at http://www.hindawi.com
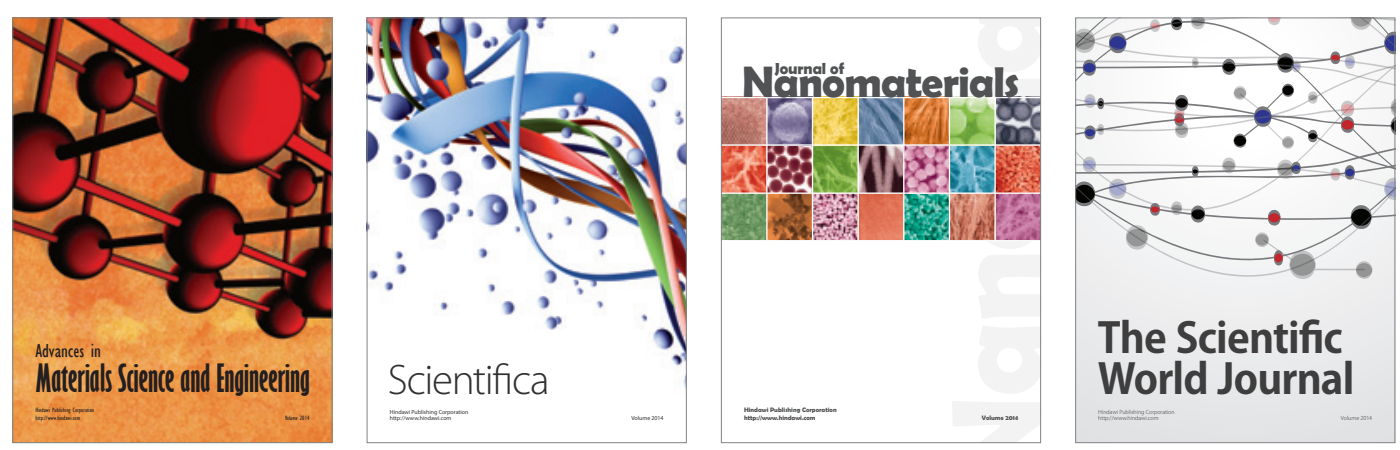

\section{The Scientific World Journal}
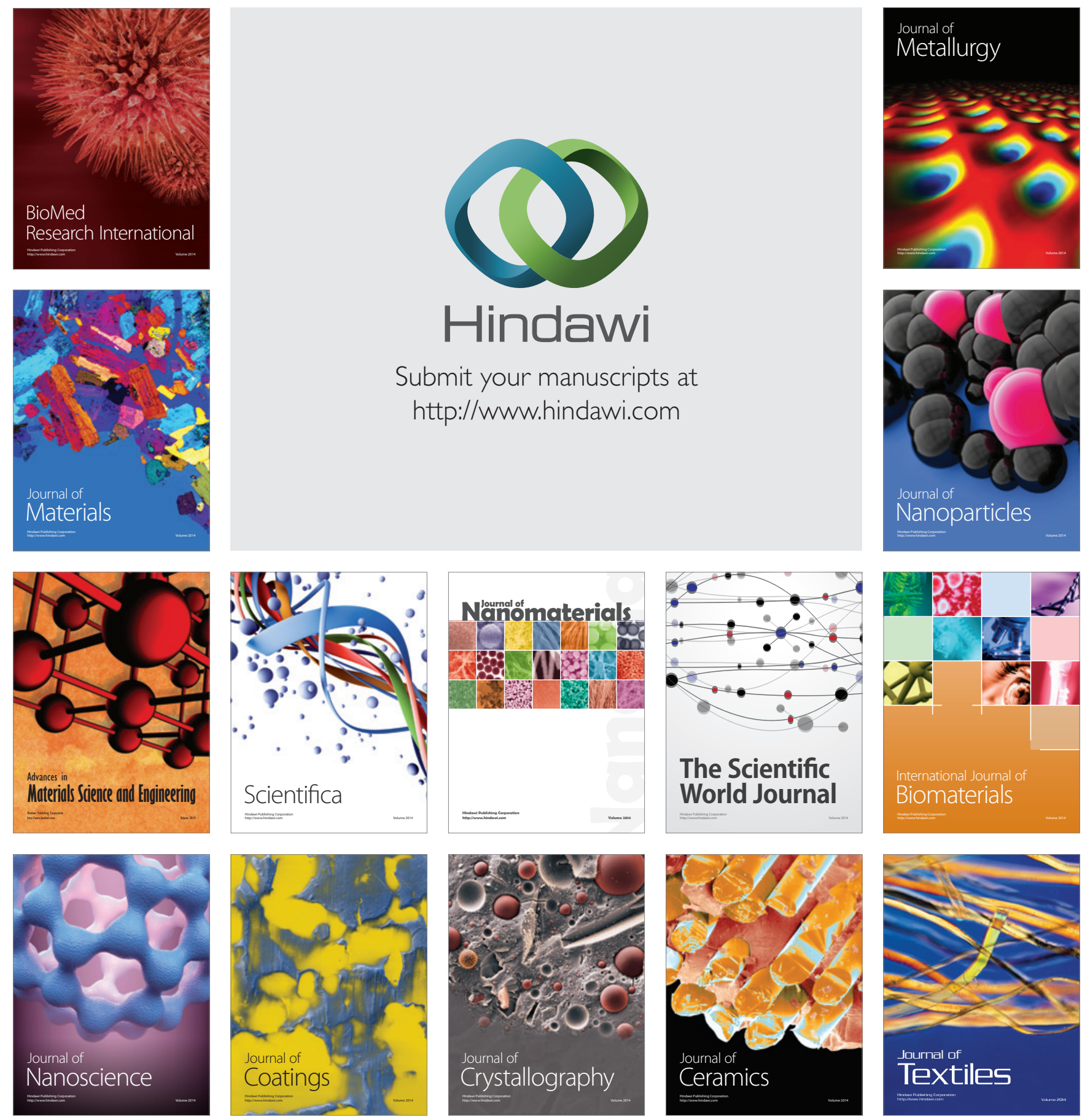